\title{
Revista de História e
}

Historiogratia da Educação

\section{HISTÓRIA, NARRATIVA E ENSINO: DIÁLOGOS, LIMITES E POSSIBILIDADES DE UMA REFLEXÃO TEÓRICA}

\author{
Erinaldo Vicente Cavalcanti* \\ lattes.cnpq.br/1521193440788494
}

\begin{abstract}
Resumo: A narrativa foi - e é - objeto de reflexão na ciência história por diferentes autores e distintas abordagens. Este artigo acompanha o movimento de análise que tematiza a narrativa histórica, a fim de ampliar a reflexão acerca do "estatuto narrativo" da História acadêmica e didática e entender os limites e as possibilidades de sua pretensão em representar o passado. Com essa problematização, almeja-se colocar a narrativa como foco de análise no ensino de História como caminho passível para enfrentar as disputas de narrativas que perfilam o cotidiano da sala de aula. Para tanto, recorre-se a diferentes autores, em especial Paul Ricœur, para explicitar em que consiste a narrativa histórica e quais os procedimentos que atribuem legitimidade e reconhecimento a sua representação do passado. Pelo arcabouço teórico mobilizado, defende-se que os procedimentos constituidores da narrativa histórica podem ser acionados como uma estratégia viável para lidar com as disputas de narrativa em sala aula e promover o entendimento sobre a relação de confiança e credibilidade que esse relato escrito desfruta na tarefa de representar o passado.
\end{abstract}

Palavras- chave: História; Narrativa; Ensino; Representação.

\section{HISTORY, NARRATIVE AND EDUCATION: DIALOGUES, LIMITS AND POSSIBILITIES OF A THEORETICAL REFLECTION}

Abstract: The narrative was - and is - an object of reflection in history by different authors and different approaches. The article follows the movement of analysis that focuses on the historical narrative to broaden the reflection on the "narrative status" of History - academic and didactic - in order to understand the limits and possibilities of its claim to represent the past. With this problematization, the aim

\footnotetext{
* Doutor em História. Docente da Universidade Federal do Sul e Sudeste do Pará (Brasil). Contato: ericontadordehistorias@gmail.com.
} 


\section{Revista de História e}

\section{Historiografia da Educação}

is to place the narrative as the focus of analysis in the teaching of History as a possible way to face the disputes of narratives that appear in the daily life of the classroom. To this end, it mobilizes different authors, especially Paul Ricoeur, to explain what the historical narrative consists of and which procedures give legitimacy and recognition to its representation of the past. Through the mobilized framework, it is argued that the procedures which constitute historical narrative can be used as a viable strategy to deal with classroom narrative disputes and to promote understanding of the relationship of trust and credibility that this written report rejoices in the task of representing the past.

Keywords: History; Narrative; Education; Representation.

$$
\begin{array}{r}
* * * \\
\text { O que criou a humanidade foi a narração. } \\
\text { Pierre Janet } \\
\text { Procura-se em vão uma ligação direta entre a forma narrativa } \\
\text { e os acontecimentos tais como se produziram de fato. } \\
\text { Paul Ricœur }
\end{array}
$$

\section{Considerações iniciais}

Grécia Antiga, século V a.C. Casamento de Zeus. Banquete servido. Diversos deuses na celebração. O anfitrião da festa teria perguntado aos presentes se faltava algo em sua cerimônia. Os convidados imploraram que o dono da festa criasse seres com poderes divinos para manusear palavras e músicas e que, com elas, fossem capazes de embelezar suas obras. O manuseio daquelas "ferramentas" 


\section{Revista de História e}

\section{Historiografia da Educação}

ajudava os homens a alcançar a imortalidade. Os poetas e os bardos ${ }^{1}$ teriam, assim, sido criados.

Esse relato foi inspirado em uma passagem do livro $A$ vida do espírito, da filósofa Hanna Arendt (2010). Ao fazer referência a um poema atribuído a Píndaro, em que ele narra cenas do casamento de Zeus, a autora promove uma importante reflexão sobre o poder do ato narrativo. Ela coloca, no centro do debate, o poder criador da narrativa. Pelos relatos do poema, a narrativa como forma de contar, registrar e relatar tornaria possível alcançar a tão desejada imortalidade. Mas, não poderia ser qualquer narrativa. Os grandes feitos de deuses e homens precisavam ser embelezados e bem narrados. Citando o referido poema, a filósofa sentencia que "[...] 'a história das coisas feitas sobreviveu aos atos' e 'o que é dito torna-se imortal, se foi bem-dito'." (ARENDT, 2010, p. 152).

A narrativa, como questão/problema de estudo e pesquisa, tornou-se parte do meu percurso profissional quando fui convidado e desafiado, em 2008, a escrever um livro didático² de História, para o Estado de Pernambuco, destinado a estudantes do quinto ano e professores (as) - a maioria pedagogas - que lecionam nesse seguimento escolar. Tal foi minha surpresa, naquele momento, ao começar produzir o texto e perceber as inúmeras dificuldades e

\footnotetext{
${ }^{1}$ Pessoa encarregada de transmitir histórias; também sinônimo de "trovador" e "poeta".

${ }^{2}$ Em 2008, recebi um convite da Editora Moderna para escrever o livro didático de História para o Estado de Pernambuco. O livro, História de Pernambuco:

Pernambuco de muitas histórias, fez parte do PNLD Regional e foi adotado por uma significativa quantidade de escolas naquele estado. Mesmo sendo considerado autor do livro, e recebendo as credenciais referentes a esse lugar de autoria, defendo que não existe o personagem "autor de livro didático", mas, sim, autor de texto didático, como expressei em outro texto (CAVALCANTI, 2016).
} 


\section{Revista de História e}

Historiografia da Educação

desafios em fabricar uma narrativa para um público que não fosse formado de historiadores e historiadoras. 3

Entre os aprendizados que resultaram da experiência em produzir uma narrativa didática, destaco um que se encontra imerso em uma questão-problema fulcral da ciência histórica: nossa área de referência nos habilita e instrumentaliza apenas para dialogar com os pares especializados. Dito de outra forma, a área da História - pois é dessa que posso falar - não nos capacita a construir um produto textual que seja consumido (diga-se, entendido) por quem não é especialista nessa área. Ou seja, só sabemos dialogar com os historiadores profissionais. Essa constatação é um problema a ser enfrentado em nossa formação? A ciência histórica precisa produzir uma narrativa que seja entendida e consumida por outros segmentos sociais?

A narrativa - sobretudo a escrita - é, talvez, o principal "produto" pelo qual estabelecemos diálogos. Produzimos narrativas textuais em forma de Trabalho de Conclusão de Curso (TCC), dissertações e teses, no âmbito estritamente acadêmico. Ainda, fabricamos narrativas textuais em forma de artigos, ensaios, livros e capítulos de livros acadêmicos. Igualmente, produzimos narrativas textuais em pareceres técnicos sobre projetos, livros, artigos. Em menor percentual, os profissionais formados nessa área do conhecimento também escrevem livros ou textos didáticos em forma de narrativas. Não seria, portanto, inverossímil afirmar que a narrativa é o principal produto pelo qual uma parte de nosso trabalho é

3 Foi a partir dessa experiência que comecei a pesquisar sobre o ensino de História. Desde então, venho desenvolvendo pesquisas tematizando o ensino de História, o livro didático e a formação docente. As pesquisas que apresento neste texto são resultantes das desenvolvidas no laboratório, com o grupo de pesquisa iTemnpo e com a Linha de Pesquisa "Ensino de História, Narrativas e Documentos", vinculada ao Programa de Pós-Graduação em História (PPGHIST) da Unifesspa. Agradeço aos membros do iTemnpo pelas críticas e sugestões apontadas quando o texto foi debatido em nossos encontros. 


\section{Revista de História e}

\section{Historiografía da Educação}

representado. É por ele, também, que estabelecemos diálogos com outros sujeitos.

Essa constatação - bastante óbvia, até - não é recente nem foi feita por mim. Como ressalta Jurandir Malerba, "[...] a maior parte dos historiadores, durante a maior parte do tempo, mas sem muita consciência disso, pensa narrativamente e escreve narrativas." (MALERBA, 2016, p. 25). Portanto, problematizar a narrativa é, sem dúvida, uma questão permanente no processo de constituição dessa ciência.

O debate sobre a narrativa acompanhou o movimento pelo qual a História se fez ciência, conforme analisou François Dosse (2012). Alguns pesquisadores, como Paul Ricœur (2007), François Hartog (2011) e David Carr (2016), em diferentes momentos, já enfrentaram o debate sobre a narrativa e a problematizaram por distintas perspectivas. Alguns desses autores são mobilizados neste texto, pois suas reflexões ajudam a problematizar a tessitura constitutiva da narrativa historiográfica. De maneira especial, as análises de Paul Ricœur são mobilizadas no presente texto e ajudam a ampliar as possibilidades de apreensão e uso da narrativa como produto fabricado nessa ciência. Sendo o ensino um dos usos a que essa ciência se presta, as reflexões desses autores igualmente, podem contribuir com o debate que tematiza a narrativa como elemento mobilizado na História ensinada em sala de aula da educação básica.

Nesse sentido, as considerações apresentadas se propõem a problematizar algumas dimensões constitutivas da narrativa histórica - acadêmica e didática - ao compreendê-la como representação do passado e apresentação do presente. Nesse movimento interpretativo, almeja-se analisar a narrativa para experienciá-la como uma ferramenta que pode ser explorada no ensino de História. A proposta é explorar a "tessitura da narrativa" para torná-la uma estratégia viável a ser mobilizada em sala de aula. 


\section{Revista de História e}

Historiografia da Educação

Colocar a narrativa como centro de reflexão, no ensino de História, pode potencializar as experiências da aprendizagem histórica na sala de aula. De tal modo, ainda pode constituir-se em uma possibilidade de ensino e aprendizagem em que os conteúdos estudados não sejam trabalhados apenas de forma expositiva/conteudista em sala de aula. Trabalhar os conteúdos ensinados, explorando sua constituição narrativa, pode, igualmente, contribuir para ampliar a capacidade analítica dos nossos estudantes.

Talvez, possamos falar que exista certo consenso entre a comunidade de professores/historiadores de que o acesso aos passados pesquisados, escritos e ensinados só é possível por meio das narrativas que sobrevivem à ação do tempo. As experiências passadas chegam até o presente por meio dos diferentes registros em forma de narrativas, sejam essas jornalísticas, imagéticas, ficcionais, memorialistas, fílmicas, fotográficas, textual-acadêmicas entre outras. De tal modo, direcionar o ângulo de percepção para o processo constitutivo da narrativa didática poderá ampliar a capacidade perceptiva dos estudantes de compreender como os conteúdos trabalhados são, antes de tudo, uma construção interpretativa dos relatos narrativos.

Estudar os conteúdos, compreendendo a tessitura constitutiva das narrativas que deles chegam até o presente, e que se encontram nos livros didáticos, poderá ampliar a interpretação dos estudantes, fazendo-os questionar as diferentes narrativas com as quais lidam cotidianamente. Poderá, também, contribuir para que os estudantes entendam que os conteúdos trabalhados são, antes de tudo, fruto de uma representação narrativa, assim como os demais acontecimentos do mundo de que temos conhecimento. 


\section{Revista de História e}

Historiografia da Educação

\section{A narrativa - algumas considerações}

Pierre Janet, em 1928, sentenciava que a humanidade foi criada pela narrativa. Ou seja, para ele, foi a narração, como ato de nomear, que criou a humanidade. A experiência humana, portanto, só passou a ter existência quando foi nomeada e narrada. Por essa chave de leitura, a humanidade passou a existir quando sobre ela foi fabricado algum relato narrativo.

No Dicionário Aurélio, o termo "narrar" aparece como sinônimo de "relatar" e "contar". "Narrar" pode significar contar em detalhe uma história; do latim narrare, também significa "historiar". Assim, narrativa e história são crias de um parto em comum. Nesse sentido, é possível afirmar que é apenas por meio da narrativa - quando essa for "bem" narrada - que a história ganha existência; ou seja, é a narrativa que possibilita a sobrevivência da história de homens e mulheres no tempo.

Por essa perspectiva de análise, as experiências passadas só se tornam legíveis, no presente, por meio da narrativa, seja ela escrita, imagética ou oral. Essa é a teia que tece o campo de percepção que interconecta os tempos. $\mathrm{O}$ presente, por meio da narrativa, liga-se ao passado; e este não se torna apenas passado-pretérito, mas agrega-se ao presente como passado-presente, segundo Reinhart Koselleck (2006).

No entanto, não é qualquer narrativa. Como adverte Hannah Arendt (2010), essa precisa ser bem-dita, ou seja, bem tecida, bem costurada, pois, nós (professores/historiadores) não temos acesso ao acontecimento do passado, e sim ao passado como narrativa dos acontecimentos. Nesse movimento, a narrativa assume o estatuto não só de representação do passado, mas também de mecanismo de constituição dele; e, como tal, precisa dar conta de um conjunto de 


\section{Revista de História e}

Historiografia da Educação

normas e práticas próprias do tecido narrativo que institui a escrita historiográfica em sua versão acadêmica e/ou didática.

Paul Ricœur, em sua obra clássica, Tempo e narrativa, provocanos a pensar na configuração que o tempo adquire na e por meio da narrativa. A experiência humana do e no tempo só se torna inteligível quando é narrada, de acordo com o autor. Ou seja, o tempo e a própria humanidade são "crias" da narrativa. Essa tese pode ser direcionada para a escrita da história, seja esta acadêmica ou didática. Assim, é a narrativa que humaniza a história, tornando-a arte e feitura dos homens e instituindo-a, por extensão, como conhecimento inteligível capaz de inventariar os tempos.

Colocar a narrativa no centro das discussões, em torno da escrita da História, não significa defender que a história é uma narrativa qualquer, ou uma narrativa que se resume ou equivale apenas a um relato descritivo. Trata-se, pelo contrário, de pensar o estatuto narrativo na escrita da História em termos de composição, enredo, trama e intriga, que atribuem significados à historiografia. Todavia, como defende o filósofo francês, "[...] não se trata de defender uma história simplesmente narrativa, mas de discernir o lugar próprio da história entre as ciências e suas condições de inteligibilidade, reconhecendo o pertencimento da historiografia ao campo narrativo." (RICEEUR, 2010, p. XIV).

Portanto, a narrativa é uma espécie de fio que costura, entrelaça, imbrica histórias que se encontram e que, não raro, estão dispersas e, a princípio, sem conexão. A narrativa atribui inteligibilidade à escrita acadêmica ou didática do professor/historiador; alinhava fragmentos de histórias tecidas em tempos e espaços múltiplos e, assim, é capaz de atribuir sentido e significado às histórias pesquisadas, contadas, narradas, escritas, ensinadas e problematizadas em sala de aula. Nesse movimento, ela é uma espécie de rede de agenciamento dos 


\section{Revista de História e}

Historiografia da Educação

acontecimentos, como enfatiza Ricœur, urdida na tessitura de uma intriga analisada pela operação historiográfica.

Outra dimensão importante, no que tange às discussões com a narrativa, diz respeito a colocar em debate as intenções do historiador na prática de seu ofício. O historiador é, assim, o artífice da tapeçaria narrativa; é o mestre-artesão que molda, dá forma, inventa e conduz os fios das explicações que atribuem inteligibilidade aos fatos narrados, escritos e ensinados. Ou, como escreve Ricœur,

[...] reconstruir os vínculos indiretos da história com a narrativa é, em última instância, trazer à tona a intencionalidade do pensamento historiador mediante o qual a história continua a visar obliquamente o campo da ação humana e sua temporalidade básica." (RICEUR, 2010, p. 153). Destaques do original.

Não só o tempo ganha existência pela narrativa; o espaço também. No final da década de 1970, Michel de Certeau vai asseverar que os relatos são constituidores dos espaços. Ao fazer analogia aos transportes públicos, na cidade de Atenas contemporânea, ele sentencia que, todo dia, os relatos "[...] atravessam e organizam os lugares; eles os selecionam e os reúnem num só conjunto; deles fazem frases e itinerários. São percursos de espaços. Vendo as coisas assim, as estruturas narrativas têm valor de sintaxes espaciais." (CERTEAU, 1994, p. 199). Os relatos narrativos, pois, transformam os lugares na medida em que nomeiam, classificam, ordenam, identificam e atribuem sentidos e significados. Ou seja, são as narrativas que criam os espaços e, poderíamos acrescentar, que constroem os tempos.

Nesse sentido, compartilho da leitura que apreende a narrativa como criadora do mundo e, como tal, torna-o possível e inteligível. Ela permite que o mundo seja lido, entendido e interpretado. Não é novidade, mas é oportuno reforçar que temos acesso aos acontecimentos outrora vividos, senão por meio dos vestígios 


\section{Revista de História e}

\section{Historiografía da Educação}

narrativos. Só temos acesso aos passados vividos pela humanidade, por meio das diferentes narrativas construídas para atender a distintos interesses, que não só os da História. A narrativa é o vestígio que possibilita que as experiências humanas ultrapassem as fronteiras do tempo, permitindo que o ocorrido, em tempos passados, seja conhecido hoje, em tempos presentes, e possa ser projetado para tempos futuros.

\section{Narrativa histórica e representação do passado}

Paul Ricœur (2007), em seu clássico livro, A memória, a história, $o$ esquecimento, elabora uma densa reflexão sobre a dimensão narrativa do fazer historiográfico. Ele coloca no centro da análise a questão fulcral sobre a pretensão da narrativa histórica de representar o passado. Quais os limites para essa questão? Quais os desafios? Quais as implicações? Pode, a narrativa histórica, representar o passado? Em que consiste essa representação? Em que se diferencia de outras representações? Quais referentes lhe atribuem reconhecimento e inteligibilidade?

Uma chave de interpretação, oferecida por Ricœur, talvez ajude a enfrentar a questão que beira uma aporia. Devemos, pois, fazer um primeiro esforço no sentido de não querer atribuir uma relação de complementariedade entre representação narrativa e acontecimento representado. A narrativa histórica, por mais que se encontre conectada à experiência representada, não estabelece, com esta, uma relação de causalidade ou determinação. A narrativa histórica não é determinada pelo fato narrado, ainda que não possa separar-se dele.

No entanto, isso não significa que há uma relação de antinomia entre a narrativa histórica e a História narrada. Como ressaltou o filosófico David Carr (2016), não há um divórcio entre a narrativa histórica e aquilo que se denomina como realidade histórica 


\section{Revista de História e}

Historiografia da Educação

representada pela narrativa. A narrativa histórica não é uma construção alienígena, apartada da experiência sobre a qual produz um relato. Em outras palavras, narrativa histórica e história narrada não se excluem; são distintas, mas precisam uma da outra para existir.

Nesse sentido, é oportuno destacar que a narrativa histórica não é uma cópia do acontecimento narrado. Por essa linha de interpretação, Ricœur assevera que

[...] procura-se em vão uma ligação direta entre a forma narrativa e os acontecimentos tais como se produziram de fato; a ligação só pode ser indireta através da explicação e, aquém desta, através da fase documental, que remete, por sua vez, ao testemunho e ao crédito dado à palavra alheia. (RICEUR, 2007, p. 256).

Para o autor, é necessário estabelecer as distinções entre narrativa e acontecimento narrado, e procurar as conexões entre a narrativa histórica, a fase explicativa/compreensiva e a fase documental.

Hayden White (1994 e 2019), ao defender que a narrativa produzida pelos historiadores, em certas dimensões, era constituída pelos mesmos elementos que outras narrativas ficcionais, provocou desconforto e mobilizou a crítica de uma parcela dos historiadores. Para ele, a narrativa escrita pelos historiadores mantém semelhanças e aproximações com a narrativa de ficção, na medida em que o historiador, ao escrever, faz uso dos mesmos tropos linguísticos em sua produção discursiva. A narrativa produzida pela ciência histórica, como linguagem escrita, aciona os mesmos elementos mobilizados pela narrativa ficcional. Nessa dimensão, a escrita histórica faz uso dos elementos semânticos na construção dos enunciados, recorre às figuras de linguagem e à sintaxe. Também constrói enredos, mobiliza personagens, agencia tempo, espaço e narrador, como categorias que são utilizadas igualmente na narrativa ficcional. Adicionemos à 


\section{Revista de História e}

Historiografia da Educação

equação que ambas as narrativas mobilizam os mesmos elementos gramaticais para representar seus objetos.

A relação entre a narrativa produzida pela ciência histórica e a ficção também foi registrada por Michel de Certeau. Para ele, em alguma medida, a ficção se reencontra com o produto escrito pela historiografia resultante do manuseio dos vestígios do passado. Para o autor, "[...] o passado é, também, ficção do presente." (CERTEAU, 2007, p. 21). Ou seja, a narrativa fabricada pelo historiador, no presente, em certa medida, cria e representa o passado. Nesse sentido, o passado é reinventado como criação/ficção, no presente, pelo historiador. Por esse ângulo de percepção, Ricœur sentenciou que "[...] consideradas sob o ângulo da imaginação da linguagem, narrativa histórica e narrativa de ficção pertencem a uma única e mesma classe, a das 'ficções verbais'." (p. 263/264. Destaque do original).

Entender a tessitura que constitui a narrativa histórica e em que ela se diferencia de outras narrativas não é uma questão retórica. Compreender seu processo de gestação não é uma questão de interesse gramatical. Problematizar a narrativa histórica não é uma questão de cunho semântico. É, pelo contrário, entender as relações políticas no campo das disputas discursivas sobre a pretensão da narrativa histórica em representar o passado.

É fundamental, portanto, entender as singularidades constitutivas da narrativa histórica, não mais para definir em que ela se distingue da narrativa de ficção, para hierarquizar e definir qual narrativa é fiel ou verdadeira. Mas, é fundamental compreender o processo de construção da narrativa produzida pela ciência histórica para ampliar a reflexão sobre sua pretensão em representar o passado e, dessa forma, mobilizá-la como estratégia para o estudo e o ensino de História.

Por esse percurso analítico, entender que existem elementos comuns à narrativa histórica e à narrativa ficcional não significa, no 


\section{Revista de História e \\ Historiografia da Educação}

entanto, dissolver as distinções existentes. Compreender que, na escrita produzida pela ciência histórica, há elementos comuns e presentes em outros gêneros narrativos (sobretudo na ficção), não significa dizer que essas narrativas se equivalem. Por conseguinte, não significa que são, no todo, semelhantes, como se a escrita produzida pela História fosse regida pelas mesmas normas e regras pelas quais são produzidas a escrita ficcional. Não. Compreender em que se aproximam e em que se assemelham serve para reforçar, inclusive, em que se distanciam e se diferenciam.

As reflexões de Paul Ricœur sugerem um caminho possível para enfrentar os limites sobre a representação do passado construída pela narrativa histórica e em que esta se diferencia da narrativa ficcional. São análises que podem ser mobilizadas, a meu ver, tanto no debate especificamente acadêmico, como nas reflexões desenvolvidas na sala de aula, no que tange à pretensão da narrativa histórica em representar o passado.

A narrativa histórica é o desdobramento de um conjunto de práticas, cujo resultado é a fabricação de um produto escrito, ou seja, de um texto. Essas práticas são regidas por regras específicas que determinam um conjunto de fazeres e legitimam um determinado tipo de escrita, ao passo que proíbem outro, como demonstrou Certeau (2007). A fase "documental" e a fase "explicativa/compreensiva", para Paul Ricœur, antecede e torna possível a fase da representação, produtora de uma narrativa. Essas fases procedimentais, de forma indissociável uma das outras, constroem as condições de possibilidade que atribuem sentido e distinção à narrativa histórica. Esta, pois, é um produto textual que resulta de procedimentos verificáveis e que mobiliza vestígios documentais e procedimentos de cunho explicativo e compreensivo, os quais resultam em uma representação do passado. Essa representação narrativa é constituída por normas e 


\section{Revista de História e}

Historiografia da Educação

procedimentos reconhecidos e validados por um corpo de intelectuais, e legitimada socialmente.

É preciso compreender que a fase da representação histórica ou da representância, como prefere Ricœur - fabricada pela narrativa escrita não está separada de suas fases anteriores. Não é uma ação à parte, como se fosse uma construção desvinculada da atividade meticulosa da pesquisa documental e da compreensão/explicativa. $\mathrm{Ou}$ seja, se a narrativa historiográfica almeja produzir uma dada representação do passado, isso só é possível quando articula e conecta a fase documental e a fase compreensiva/explicativa à fase representativa. Nas palavras do autor, "[...] a representação, tanto em seu aspecto narrativo como sob outros aspectos, não se acrescenta de fora à fase documental e à fase explicativa, as acompanha e as sustenta." (RICEUR, 2007, p. 251).

Por essa chave de entendimento, não devemos buscar apenas na narrativa histórica - ou seja, na fase da representação narrativa (a escrita) - os elementos pelos quais se pode atribuir sentido e reconhecimento à representação do passado. É necessário identificar e reconhecer, na dimensão escrita da narrativa histórica, os elementos e procedimentos das fases que antecederam e que acompanham, concomitantemente, sua construção textual. Nas palavras de Ricœur:

É preciso articular pacientemente os modos da representação com os da explicação/compreensão e, através desses, com o momento documental e sua matriz de verdade presumida, a saber, o testemunho daqueles que declaram ter se encontrado no local onde as coisas aconteceram. Nunca acharemos na forma narrativa enquanto tal a razão dessa busca de referencialidade (RICEUR, 2007, p. 266/267).

Nesse sentido, os procedimentos constitutivos da narrativa histórica, em suas três fases, estabelecem as relações necessárias com os critérios que atribuem legitimidade à escrita histórica em sua pretensão de representar o passado. A referencialidade pela qual a 


\section{Revista de História e}

\section{Historiografia da Educação}

narrativa histórica distingue-se da narrativa ficcional, por exemplo, e pela qual desfruta do estatuto de reconhecimento não reside, pois, nas figuras de linguagem ou nos recursos gramaticais mobilizados na construção linguística do discurso. Portanto, não se encontram, na dimensão da linguagem, os elementos e procedimentos instituidores a partir dos quais a narrativa histórica busca representar o passado. Em que consistiria, afinal, a referencialidade do regime historiográfico para atribuir legitimidade à narrativa da ciência histórica? Paul Ricœur defende a tese de que "[...] ela não pode ser discernida unicamente no plano do funcionamento das figuras [de linguagem] que o discurso histórico assume, mas deve transitar pela prova documental, pela explicação causal/final e pela composição literária. Tal arcabouço tríplice continua a ser o segredo do conhecimento histórico.” (2007, p. 263). Esse procedimento, que conecta a fase da representação historiadora às suas duas outras fases operatórias, não fez parte das reflexões estabelecidas por Hayden White, de acordo com Ricœur.

\section{Disputas narrativas e ensino: combates pela História}

Como lidar com as disputas de narrativas que passam a ocupar um lugar cada vez mais denso e tenso nas aulas de História? Dizer que essa ou aquela é uma narrativa histórica, por ter sido elaborada por um especialista, parece não surtir mais os efeitos desejados. Registrar que uma dada narrativa está presente nos livros didáticos de história e que, portanto, é confiável, parece que também não tem sido suficiente para enfrentar as disputas de narrativas. Dizer que certa narrativa se encontra presente nos livros acadêmicos produzidos pela ciência histórica, parece que, igualmente, não tem produzido os efeitos necessários para garantir força na concorrência com outras narrativas. 


\section{Revista de História e}

\section{Historiografia da Educação}

Nesse sentido, talvez tenhamos que colocar a narrativa como objeto central de reflexão na aula de História e, por conseguinte, promover uma reflexão para apresentar e entender o que afinal produz e atribui sentido, reconhecimento e legitimidade para a narrativa histórica, seja ela na versão científica ou didática. No entanto, essa problematização não deve ter a pretensão de atribuir à narrativa histórica o estatuto de única a ser capaz de representar o passado.

É sobre essa perspectiva que a discussão se coloca, almejando ampliar as reflexões. Sabemos que, em nossa experiência de tempo presente, avolumam-se a produção e a comercialização de diferentes narrativas sobre as mais diversas temáticas. Sabemos, igualmente, que nossos estudantes chegam aos bancos das escolas alimentados, cada vez mais, por distintas narrativas produzidas pelas plataformas de interação e amplamente divulgadas pelas redes virtuais de comunicação. São narrativas produzidas em diferentes lugares de enunciação, comercializadas e amplamente circuladas nos aplicativos virtuais de comunicação.

Portanto, a discussão se propõe a ampliar esse debate por entender que a devida clareza acerca dos elementos constitutivos da narrativa histórica é um caminho que pode ser percorrido. Por conseguinte, mobilizar a reflexão sobre os procedimentos pelos quais se atribuem reconhecimento e legitimidade ao relato narrativo, produzido pela História, pode ser um recurso acionado para lidar com a diversidade de narrativas que nossos estudantes consomem e que, não raro, também têm a pretensão de representar o passado. São narrativas que também concorrem com aquela fabricada pela ciência histórica, e que entram na disputa de representar o passado.

No texto, "Essa história é de verdade? a narrativa escolar e seus matizes", Helenice Rocha faz uma importante reflexão sobre a centralidade da narrativa, especialmente sobre a "narrativa escolar" no 


\section{Revista de História e}

Historiografia da Educação

ensino de História. Em diálogo com Jean Hébrard, Rocha afirma que, segundo o autor,

[...] precisamos da narrativa para entender o que acontece em nosso mundo e atribuir sentido a ele, asseverando ainda, que as narrativas ficcionais e históricas têm papeis diferentes. A narrativa ficcional possibilita a experimentação dos mundos possíveis e a histórica dá sentido ao mundo em que vivemos em relação ao passado. (ROCHA, 2015, p. 214).

Que precisamos das narrativas para entendermos o que acontece no mundo, parece ser um ponto consensual, sobretudo, porque só temos acesso às experiências passadas por meio das narrativas que delas são produzidas. Também parece não haver discordância de que as narrativas ficcionais e históricas são distintas e desempenham papeis igualmente distintos, como já mencionado no diálogo com Paul Ricœur (2007). No entanto, afirmar que a narrativa de ficção possibilita experimentar o mundo como possibilidade, ao passo que a narrativa histórica permite dar sentido ao mundo em que vivemos em relação ao passado, talvez não seja um consenso.

Por essa linha de interpretação, apenas a narrativa histórica teria poder para atribuir sentido ao "mundo real" (mundo em que vivemos), uma vez que a ficcional apenas permitiria atribuir sentido a um mundo imaginativo, ou seja, "um mundo não real". A narrativa ficcional pode, igualmente, atribuir sentido ao mundo em que vivemos, e narrar e representar um acontecimento do "mundo real". No entanto, o sentido que ela é capaz de atribuir é distinto daquele oferecido pela narrativa histórica. É diferente pelos procedimentos constitutivos de cada narrativa. É distinto pela relação cultural que se estabelece entre o leitor e cada tipo de narrativa, ou, como defende Ricœur, pelo "pacto estabelecido".

É importante que o professor tenha clareza de que, apesar de existir alguma vizinhança entre narrativa de ficção e narrativa 


\section{Revista de História e}

Historiografia da Educação

histórica, elas não são sinônimas. Mais uma vez, Paul Ricœur pode ser acionado nessa situação. Ele é categórico ao afirmar que narrativa histórica e narrativa de ficção são gêneros literários distintos, e antinômicos até. Para ele, "[...] uma coisa é um romance, mesmo realista; outra coisa, um livro de história. Distinguem-se pela natureza do pacto implícito ocorrido entre o escritor e seu leitor.” (2007, p. 274). Em seguida, o autor sentencia:

Ao abrir um livro de história, o leitor espera entrar, sob a conduta do devorador de arquivos, num mundo de acontecimentos que ocorreram realmente. Além disso, ao ultrapassar o limite da escrita, ele se mantém em guarda, abre um olho crítico e exige, se não um discurso verdadeiro comparável ao de um tratado de física, pelo menos um discurso plausível, admissível, provável, e, em todo caso, honesto e verídico; educado para detectar as falsificações, não quer lidar com um mentiroso (RICEUR, 2007, p. 275).

Essa reflexão de Ricœur é importante, pois, como ressalta o autor, uma das dimensões que atribuem sentido e reconhecimento à narrativa histórica se encontra na relação que o leitor (aluno, professor ou qualquer outro cidadão) constrói com o texto escrito pela ciência histórica. Ou seja, não se trata apenas da estrutura semântica, dos argumentos usados, dos documentos mobilizados, das figuras de linguagem acionadas. A narrativa histórica permite, pois, estabelecer uma relação de confiança entre o que está narrado e como está relatado. Essa relação de credibilidade não almeja atribuir à narrativa histórica o poder de representar os acontecimentos tal como ocorreram. Mas, apresenta-se como uma narrativa confiável, na medida em que oferece os elementos e os procedimentos pelos quais se constitui. É uma narrativa "verificável".

A relação de confiança pode ser fortalecida à medida em que se explicite que a narrativa historiográfica - em sua versão acadêmica ou didática - não deve ser entendida como um reflexo das experiências 


\section{Revista de História e}

Historiografia da Educação

relatadas. O pacto estabelecido e os sentidos estimulados não podem projetar uma relação de exata correspondência entre o acontecimento narrado e a representação narrativa elaborada na escrita dos livros didáticos ou acadêmicos.

É necessário fazer um esforço para romper os vínculos que tentam estabelecer uma sincronicidade entre o texto escrito e a história do conteúdo ou acontecimento estudado. As conexões existentes entre o conteúdo estudado e a narrativa escrita, presente nos livros, não podem ser entendidas como se existisse uma relação de determinação e causalidade entre essas duas dimensões. Em outras palavras, a narrativa histórica não é uma cópia do conteúdo estudado e, como tal, não há uma relação de "absoluta fidelidade" entre a representação narrativa e o conteúdo representado no relato escrito. Nesse sentido, a narrativa não pode ser mobilizada como se fosse capaz de oferecer uma representação fidedigna dos acontecimentos narrados, como se fosse possível existir uma correspondência, em termos de "encaixe", entre a narrativa histórica e o fato narrado. É importante ressaltar que nenhuma narrativa é capaz de produzir um relato fiel e inquestionável sobre $\mathrm{o}$ acontecimento relatado.

A relação de confiança pode ser fortalecida, também, ao recorrerse ao fundamento pelo qual se apreende a escrita historiográfica $-\mathrm{em}$ sua versão acadêmica ou didática - como uma narrativa produzida por normas e regras reconhecidas por um corpo de profissionais qualificados. Ou seja, não é construída de qualquer forma. Em se tratando da narrativa produzida pelo livro didático, ainda é necessário explicitar algumas práticas que singularizam e tornam possível que essa narrativa seja elaborada.

É importante ressaltar que esta reflexão não almeja transformar a aula de História em um palco de disputas para definir qual narrativa é ficcional e qual é histórica. Também não deve ter a pretensão de atribuir à narrativa de ficção o estatuto de relato fantasioso, ao passo 


\section{Revista de História e}

Historiografia da Educação

que atribuir-se-ia à narrativa histórica o lugar do relato verdadeiro e inquestionável. Deve-se pretender, com isso, compreender o estatuto narrativo da escrita histórica para entender seus limites e possibilidades acerca de sua pretensão em representar o passado e, dessa forma, ampliar seu potencial para concorrer com outras narrativas. Afirmar que uma narrativa é verídica, porque é produzida pela ciência histórica, e que a outra é inverídica, porque não é fabricada pela ciência, talvez não seja o melhor argumento nem o melhor caminho a ser percorrido.

É importante registrar que problematizar a narrativa, nas aulas de História, não significa "perder tempo". Sabemos que o tempo é um fator matricial para os (as) professores (as) de História na educação básica, sobretudo com o vasto cardápio de conteúdos a serem trabalhados durante o ano. A sugestão não é trabalhar a narrativa desvinculada do conteúdo, como se fosse um assunto ou conteúdo à parte. Não. A opção é trabalhar o conteúdo, problematizando a narrativa pela qual ele é representado. O que está se alterando é o percurso e o ângulo de percepção.

Ao invés de servir aos estudantes uma longa lista de conteúdos distribuídos pelo sumário dos livros, por meio de uma exposição quase sempre descritiva, cronológica e linear - será oferecido um menu sobre como os referidos conteúdos são construídos, como são fabricados e representados até chegarem a ser "degustados" em sala de aula. Essa opção pode até contribuir para que os assuntos saboreados não sejam esquecidos após serem experimentados em forma de atividades de aprendizagens e/ou avaliativas. Dessa forma, busca-se problematizar como os conteúdos são elaborados para ampliar o entendimento sobre como eles representam os passados estudados.

Essa opção não almeja transformar os jovens da educação básica em pequenos historiadores. Pelo contrário. Objetiva contribuir com a construção crítica do mundo em que vivem nossos alunos e alunas; um 


\section{Revista de História e}

\section{Historiografía da Educação}

lugar marcado pelas experiências das disputas narrativas cada vez mais densas. Pretende ampliar as capacidades cognitivas pelas quais os alunos consomem diferentes narrativas no cotidiano da vida. À medida em que o estudante tiver a oportunidade de estudar os conteúdos, compreendendo como são produzidos enquanto construção narrativa, poder-se-á ampliar a sua capacidade de problematizar as demais narrativas que consome no dia a dia.

Nesse sentido, direcionar o foco de atenção para a narrativa pode recolocar o debate para compreender que uma aula de História é um ato narrativo. Mesmo quando a aula se resume a uma exposição cronológica, ela é apresentada por meio de uma narrativa que inventa, representa a apresenta tempos, espaços e pessoas. Nessa perspectiva, o historiador Durval Muniz de Albuquerque Júnior é enfático, e destaca que "[...] esquecemos, talvez, que dar aula é narrar, que a história é um relato, que a historiografia é um gênero narrativo e, tal como o espaço da aula, dependente da narrativa para existir." (ALBUQUERQUE JÚNIOR, 2016, p. 31).

\section{Narrativa e livro didático: diálogos e possibilidades}

A principal narrativa consumida na sala de aula, na forma de conteúdos aprendidos e ensinados, é servida por meio dos livros didáticos. A literatura especializada mostra que o livro didático ainda continua sendo a principal - e, às vezes, a única - ferramenta disponível para o professor na sala de aula. 4 Nessa perspectiva, o livro didático pode ser apropriado e mobilizado como uma "complexa narrativa" pela qual certos passados são produzidos, apresentados e

\footnotetext{
4 Há uma significativa produção acadêmica que tematiza o livro didático como ferramenta de trabalho docente na sala de aula. Sugere a leitura de Abud (2007); Miranda e Luca (2004) e Oliveira e Stamatto (2007).
} 


\section{Revista de História e}

Historiografia da Educação

representados de forma escrita em nosso presente. Contudo, atribuir ao livro didático de História a denominação "narrativa complexa" não significa dizer que outras formas de narrativas históricas, ficcionais ou literárias, sejam menos ou nada complexas.

Com essa categorização, deseja-se, tão somente, explicitar o processo de produção da narrativa didática. Ou seja, para apreender o livro didático como narrativa, faz-se necessário mostrar o percurso de produção dessa narrativa. Com isso, é preciso ressaltar que ela é construída por diferentes profissionais de distintas áreas, desde o professor/pesquisador (que escreve o texto no computador), até os profissionais da área de design gráfico, editores e revisores como destacam Cavalcanti (2016) e Bittencourt (2009). Também é indispensável apresentar aos estudantes as condições que tornam possível que determinada narrativa seja construída, sobretudo por meio de políticas públicas garantidas pelo Programa Nacional do Livro Didático (PNLD). 5

É fundamental que professores e estudantes compreendam, minimamente, o conjunto de relação que possibilita que tal narrativa seja produzida. Assim, é preciso apresentar as etapas pelas quais a narrativa vai ganhando corpo e existência; ou seja, deve-se mostrar os procedimentos ligados à produção textual e à utilização dos recursos documentais. Da mesma forma, é importante apresentar, mesmo que de forma rápida, os procedimentos avaliativos e os critérios presentes no PNLD, que permitem com que certos enunciados se façam presentes ao passo que proíbem outros de aparecerem nas narrativas didáticas. Além disso, é necessário mostrar os procedimentos para a escolha dos livros, desde o momento que são aprovados, até sua chegada à escola.

5 Há uma vasta e importante quantidade de referências sobre o PNLD como objeto de reflexão para se problematizar o livro didático de História. Nesse sentido, sugere-se a obra produzida e organizada por Rocha, Reznik e Magalhães (2017), Caimi (2018) e Munakata (2012). 


\section{Revista de História e}

\section{Historiografia da Educação}

Nesse sentido, a degustação dos conteúdos, em aula, será dada de forma concomitante com a apresentação do processo de preparo, explicando, também, quais os ingredientes, os temperos, os sabores e as formas de apresentação contidos naquela narrativa. Ou seja, ao invés de servir uma narrativa seca, fria e sem sal sobre os conteúdos, essa é servida, simultaneamente, à apresentação de seu processo de fabricação e de seu percurso de preparo. A adição desses ingredientes poderá contribuir para uma boa refeição e evitar, talvez, indigestão ou amnésia.

Assim, as reflexões sobre a narrativa de um determinado conteúdo podem ser ampliadas ao se explorar como os documentos são usados e mobilizados na construção da escrita e como concorrem para representar o acontecimento narrado. Tomando essa sugestão como possibilidade de trabalho, o professor poderá escolher um conteúdo específico e estudar quais documentos os autores usaram como fonte para elaborar as narrativas.

Uma vez experimentada essa proposta, pode-se começar o estudo do capítulo (ou do conteúdo), fazendo um levantamento sobre os tipos de fontes que os (as) autores (as) usaram para escrever a narrativa. Nessa perspectiva, identificam-se quais fontes foram mobilizadas e qual lugar ocupam no texto. $\mathrm{O}$ uso da fonte, na produção textual, pode ser acionado para registrar as diferentes versões que o acontecimento estudado desfruta. Esse registro é importante para compreender como cada fonte utilizada pode mostrar, de distintas maneiras, certos aspectos ou dimensões acerca de um mesmo assunto. Nesse sentido, é oportuno ressaltar que as fontes mobilizadas não foram produzidas pelos autores da narrativa didática, nem foram fabricadas com o objetivo de servirem de fontes para um livro de História. Mostram, portanto, que a representação construída pela narrativa histórica não foi uma invenção fantasiosa da cabeça de quem escreveu o texto/livro. 


\section{Revista de História e}

\section{Historiografia da Educação}

Essa leitura pode ser demasiado óbvia para professores/ pesquisadores. No entanto, pode não ser para muitos estudantes da educação básica, que podem se questionar por que a narrativa do livro didático é confiável e outra que circula pelas redes sociais, por exemplo, não é. Essa reflexão pode ser acionada, igualmente, para mostrar que o mesmo tema ou conteúdo estudado também desfruta de diferentes versões narrativas a seu respeito, o que também pode ser explorado para mostrar a importância de refletirmos sobre as diversas narrativas que os acontecimentos produzem, e para reforçar os perigos de uma história única (ADICHIE, 2019).

Essas abordagens devem ser propostas para que os estudantes compreendam que os documentos mobilizados não são os acontecimentos representados. Assim sendo, acredito que, para professores e alunos, tão importante como usar a narrativa textual dos livros para falar sobre um dado acontecimento, é demonstrar os procedimentos constitutivos pelos quais a narrativa foi produzida, ganhou materialidade e pôde ser consumida. Em outras palavras, tão importante quanto saber o que se narra, no livro, é compreender como se narra.

A professora Carmen Teresa Gabriel Anhorn faz uma importante reflexão sobre as contribuições de Paul Ricœur sobre a potencialidade da narrativa, como uma espécie de guardiã do tempo e da história dos homens no próprio tempo. É a narrativa, pois, que, de forma heterogênea, cria e representa a humanidade. Para a autora, isso significa que

[...] a formação de enredo, no caso da narrativa histórica, traz a possibilidade de apreendê-la como estando sempre aberta a múltiplas inteligibilidades produzidas no encontro entre o mundo do texto (a história ensinada nos livros didáticos e/ou nas aulas dessa disciplina, por exemplo) e o mundo do leitor (as diferentes subjetividades posicionadas como alunos/as de história em contextos escolares). (ANHORN, 2012, p. 202). 


\section{Revista de História e}

Historiografia da Educação

Para ampliar a compreensão sobre como a narrativa apresenta e representa o conteúdo narrado, uma possibilidade viável é direcionar o ângulo de percepção para os elementos de sua composição. Assim, caracteres semânticos e gramaticais são importantes elementos que permitem que a narrativa histórica, como construção verbal, seja configurada de forma inteligível. Quando devidamente articulados, esses elementos permitem com que a narrativa produza uma síntese do heterogêneo no plano da representação. Para Paul Ricœur

[...] na medida em que as personagens da narração - os caracteres - são compostas em intriga ao mesmo tempo em que a história narrada, a noção de identificação narrativa, correlativa daquela de coerência narrativa, é suscetível, por sua vez, de transposições notáveis no plano histórico. (RICEUR, 2007, p. 256).

Para o autor, esses caracteres elevados ao lugar de personagem da narrativa se constituem em elementos-chave e, juntos com o acontecimento sobre o qual se produz uma representação, tornam possível a narrativa histórica. Para ele, "[...] as personagens da narrativa são inseridas na intriga ao mesmo tempo em que o são também os acontecimentos que, juntos, constituem a história narrada." (RICEUR, 2007, p. 276/277).

Munidos com essas reflexões, é possível conduzir o ângulo de percepção para certas áreas ou certos elementos do tecido da narrativa didática. Como construção verbal, é possível identificar, na narrativa histórica do livro didático, os sujeitos das orações gramaticais, os pronomes de tratamento, a flexão verbal e nominal, os adjetivos e as conjunções para refletir como a História é quase sempre produzida e narrada "no" gênero masculino. Esses elementos gramaticais aparecem quase sempre flexionados para o sujeito masculino. São, portanto, indicativos de uma determinada maneira de se apreender e escrever a 


\section{Revista de História e}

Historiografia da Educação

História. No texto principal da narrativa presente nos livros didáticos, a flexão verbal e nominal é, predominantemente, do gênero masculino.

A representação produzida por essa narrativa nos livros didáticos pode ser igualmente explorada, tematizando a presença do gênero masculino nos conteúdos narrados. Ao direcionar o ângulo de percepção para essa problemática, é possível identificar quais sujeitos aparecem como personagens na representação. Nesses termos, pode ser uma variável interpretativa interessante identificar e catalogar quais são os sujeitos-personagens que aparecem representados na narrativa didática. Ao estudar o chamado Feudalismo ou a Grécia Antiga, por exemplo, pode-se fazer um percurso analítico mostrando quais são os personagens que aparecem na escrita, como aparecem e qual lugar ocupam no acontecimento narrado. Também pode ser adicionado à reflexão o registro sobre quem são os sujeitos em termos de idade, cor, etnia e sexo.

Identificar esses e outros elementos, na representação das histórias narradas, pode e deve contribuir para repensar como a História ensinada é construída, narrada e produzida. Quais visibilidades ela permite. Quais dizibilidades ela constrói. Essas reflexões podem, igualmente, contribuir para ampliar o entendimento acerca de como os jovens ou os idosos são tratados pela História, seja ela escrita e pesquisada pela ciência ou ensinada, aprendida e problematizada na sala de aula. Essa reflexão também se aplica à problemática da "cor" como elemento identificador de um tipo de "raça" ou etnia na História. Como são tratados, atualmente, crianças, mulheres e homens negros? Que lugar ocupam nas narrativas que perfilam os mais variados meios de comunicação? Refletir sobre essas questões pode ampliar o entendimento sobre o lugar ocupado por esses grupos nas representações das narrativas didáticas e no cotidiano das relações da vida prática. 


\section{Revista de História e}

Historiografia da Educação

Igualmente importante é refletir sobre a figura da mulher nas narrativas presentes nos livros didáticos. As mulheres quase sempre são invisibilizadas, e não apenas no lugar da autoria da produção das narrativas. Elas são também ignoradas nas referências gramaticais, quando expressões semânticas são flexionadas, na oração, apenas para a concordância com o gênero masculino. As mulheres são esquecidas como personagens constituintes das histórias narradas. Os acontecimentos sobre os quais se produzem diferentes narrativas nos livros didáticos são protagonizados por homens. Problematizar essas narrativas predominantemente masculinas é ampliar a interpretação sobre o lugar que as mulheres ocuparam no tempo. É ampliar as possibilidades de questionar as funções a elas atribuídas e, por conseguinte, refletir sobre as posições desempenhadas por mulheres e homens no cotidiano da vida prática.

Essas questões podem, também, ser exploradas nos documentos mobilizados na narrativa textual dos livros didáticos. Ou seja, não se deve apenas questionar a ausência ou a presença desses elementos no texto escrito do livro, mas também refletir como essas dimensões ou esses temas aparecem nas fontes documentais em cada capítulo. Explorar as fontes que se encontram usadas nas narrativas didáticas permite ampliar as leituras sobre os conteúdos estudados, como já sinalizado. Permite mostrar como é possível produzir narrativas diferentes sobre um mesmo conteúdo.

As fontes documentais, usadas nas narrativas textuais presentes nos livros didáticos, também podem ser acionadas para registar os procedimentos que atribuem confiança e reconhecimento à narrativa histórica, mostrando que aquela fonte tem valor de documento. De tal modo, o recurso da fonte documental pode ser explorado para mostrar e reforçar uma das fases que atribuem sentido e significado à narrativa histórica, chamada por Paul Ricœur (2007) de fase documental. Esse recurso contribui para atribuir confiança e reconhecimento à narrativa 


\section{Revista de História e}

\section{Historiografia da Educação}

histórica. É possível, pois, reforçar que a utilização de fontes documentais faz parte dos procedimentos metodológicos e são reconhecidos e validados pelos profissionais (professores/ pesquisadores) que atuam nessa área de conhecimento.

Assim, as fontes não estão inseridas nas narrativas didáticas apenas para preencher espaço no layout do livro ou para servir de ilustração, quando se trata de uma fonte imagética. Elas são consideradas registros, produzidos pelas atividades de diferentes homens e mulheres, acerca do conteúdo estudado e representado na narrativa textual. Dessa forma, ao fazer uso das fontes que se encontram presentes nos livros didáticos, os pesquisadores que escreveram a narrativa oferecem ao leitor outros registros sobre o tema narrado. Esses registros fazem parte dos procedimentos metodológicos, exigidos pela ciência histórica como requisito necessário no processo de construção das narrativas, para que essas sejam reconhecidas e consideradas válidas.

Mas, não basta apenas usar, mostrar ou citar a fonte. É necessário outro procedimento metodológico. Trata-se da explicação/ compreensão que o (a) autor (a) da narrativa textual precisa elaborar. Como ressaltou Paul Ricour, "[...] quando juntas, escrituralidade, explicação compreensiva e prova documental são suscetíveis de credenciar a pretensão à verdade do discurso histórico." (RICEEUR, 2007, p. 292). Nesse sentido, a fonte documental - que poder ser, inclusive, um testemunho, um relato de memória - é usada como a "matéria-prima" com a qual o autor da narrativa elabora e sustenta sua argumentação explicativa sobre o conteúdo narrado. Como sentenciou Ricœur, "[...] não temos nada melhor do que o testemunho e a crítica do testemunho para dar crédito à representação historiadora do passado." (RICEER, 2007, p. 293).

As fontes sustentam a explicação, atribuindo efeito de verdade ao relato escrito e não permitindo que seja elaborada uma narrativa sem 


\section{Revista de História e}

Historiografia da Educação

regras, normas e cuidados. Esses procedimentos exigem rigor e garantem que a narrativa tenha legitimidade.

Essas reflexões, no entanto, precisam estar devidamente costuradas com os objetivos que se almeja alcançar com o ensino de História. Afinal, é preciso termos clareza para que serve ensinar História. Entender quais os objetivos a serem alcançados com o ensino de História na sala de aula da Educação Básica é condição para se problematizar a narrativa.

\section{Considerações finais}

Mais de 2.500 anos nos separam das experiências narradas sobre o casamento de Zeus. Podemos até dizer que, entre o surgimento dos poetas e bardos, relatado na cerimônia do casamento, e nossa experiência de tempo presente, uma cosmologia nos separa e nos diferencia. Podemos, inclusive, discordar que manusear palavras e músicas leva à imortalidade. Podemos, inclusive, discordar que existe imortalidade. Mas, certamente, não podemos discordar que somente por meio da narrativa podemos, hoje, em pleno século XXI, conhecer parte da história de uma parcela da sociedade da Grécia Antiga.

Apenas pela narrativa podemos conhecer o universo das crenças e dos valores de parte dos povos gregos. Igualmente, é somente por meio da narrativa que conhecemos algumas práticas, saberes, desejos e sonhos de pessoas que viveram em tempos e espaços longínquos e diferentes. Somente pela narrativa tivemos conhecimento de como aquelas pessoas que formaram a sociedade grega contribuíram para a construção da história ocidental. Também não seria inverossímil afirmar que é justamente a narrativa que nos permite a conexão entre tempos tão distantes. Ela torna possível o entendimento entre espaços tão longínquos, entre pessoas tão diferentes, e entre histórias tão 


\section{Revista de História e}

Historiografia da Educașão

distintas e tão semelhantes. Somente pelas narrativas é possível aprender e ensinar essas e outras histórias. Somente a narrativa torna possível o conhecimento daquele mundo, do nosso mundo e de outros mundos.

Entender, portanto, como a narrativa histórica é construída - na versão acadêmica e/ou na versão didática - pode ser um caminho que nos possibilite continuar a criar, relatar, representar, narrar e ensinar. Compreender e nos fazer entender, narrativamente (relatando em que consiste cada fase procedimental da elaboração narrativa da ciência histórica), talvez possa ser o melhor recurso para enfrentar as disputas de narrativas em tempos marcados pelas chamadas fake news. Talvez, em alguma dimensão, possamos afirmar que, sem a narrativa, não existe História. Sem a narrativa, não é possível ensinar História. Sem a narrativa, não há mundo. Não há humano. E, sim, a humanidade foi criada pela narrativa.

\section{Referências}

ABUD, Kátia Maria. A história de cada dia: saber escolar e saber acadêmico na sala de aula. In: MONTEIRO, Ana Maria; GASPARELLO, Arlette Medeiros; MAGALHÃES, Marcelo de Souza (Org.) Ensino de história: sujeitos, saberes e práticas. Rio de Janeiro: Mauad X, 2007. ADICHIE, Chimamanda Ngozi. O perigo de uma história única. São Paulo: Companhia das Letras, 2019.

ANHORN, Carmen Teresa Gabriel. Teoria da História, Didática da História e narrativa: diálogos com Paul Ricœur. Revista Brasileira de História. São Paulo, v. 32, no 64, p. 187-210, 2012. ALBUQUERQUE JÚNIOR, Durval Muniz. Regimes de historicidade: como se alimentar de narrativas temporais através do ensino de 


\section{Revista de História e}

Historiografia da Educação

história. In GABRIEL, Carmen Teresa, MONTEIRO, Ana Maria e MARTINS, Marcus Leonardo Bomfim. (Org.). Narrativas do Rio de Janeiro nas aulas de História. Rio de Janeiro: Mauad X, 2016. ARENDT, Hanna. A vida do espírito. Rio de Janeiro: Civilização Brasileira, 2010.

BEZERRA, Holien Gonçalves. O PNLD de história: momentos iniciais. ROCHA, Helenice, REZNIK, Luís e MAGALHÃES, Marcelo de Souza (org.). Livros didáticos de história: entre políticas e narrativas. Rio de Janeiro, FGV, 2017.

BITTENCOURT, Circe M. F. Ensino de História: fundamentos e métodos. São Paulo: Cortez, 2009.

CAIMI, Flávia Eloisa. Sob nova direção: O PNLD e seus desafios frente aos novos contextos político-educativos emergentes. Revista História Hoje, v. 7, $\mathrm{n}^{0}$ 14, p. 21-40, 2018.

CAVALCANTI, Erinaldo. Livro didático: produção, possibilidades e desafios para o ensino de História. Revista História Hoje, São Paulo, v. 5, n. 9, p. 262-284, 2016.

CERTEAU, Michel de. A invenção do cotidiano. 1. Artes de fazer. Rio de Janeiro: Vozes, 1994.

2007.

. A escrita da história. Rio de Janeiro: Forense Universitária,

DAVID, Carr. A narrativa e o mundo real: um argumento a favor da continuidade. In MALERBA, Jurandir (org.). História \& narrativa: a ciência e arte da escrita histórica. Petrópolis, RJ: Vozes, 2016.

DOSSE, François. A Narrativa. In A História. São Paulo: Editora UNESP, 2012.

HARTOG, François. Disputas a respeito da narrativa. In Evidência da história: o que os historiadores veem. BH: Autêntica, 2011.

KOSELLECK, Reinhart. Futuro Passado: contribuição à semântica dos tempos históricos. Rio de Janeiro: Contraponto; Editora PUC-Rio, 2006.

MALERBA, Jurandir (org.). História \& narrativa: a ciência e arte da escrita histórica. Petrópolis, RJ: Vozes, 2016.

MIRANDA, Sonia Regina; LUCA, Tania Regina de. O livro didático de história hoje: um panorama a partir do PNLD. Revista Brasileira de História, São Paulo: Anpuh, v. 24, nº 48, p.123-144, 2004. 


\section{Revista de História e}

Historiografia da Educação

MUNAKATA, Kazumi. O livro didático: alguns temas de pesquisa.

Revista Brasileira de História da Educação, v. 12, n. 3 [30], p. 179-197, set./dez. 2012.

OLIVEIRA, Margarida Maria Dias de. Uma profissional de história em gestão de política pública: como a memória construiu minha experiência no PNLD de 2004 a 2015. ROCHA, Helenice, REZNIK, Luís e MAGALHÃES, Marcelo de Souza (org.). Livros didáticos de história: entre políticas e narrativas. Rio de Janeiro, FGV, 2017. OLIVEIRA, Margarida Maria Dias de; STAMATTO, Maria Inês Sucupira (Org.) O livro didático de história: políticas educacionais, pesquisa e ensino. Natal: Ed. UFRN, 2007.

RICEUR, Paul. A memória, a história, o esquecimento. Campinas, SP: Editora da Unicamp, 2007.

. Tempo e narrativa. Vol. 1. A intriga e a narrativa histórica.

São Paulo: Martins Fontes, 2010.

. Tempo e narrativa. Vol. 3. O tempo narrado. São Paulo:

Martins Fontes, 2010.

ROCHA, Helenice. "Essa história é de verdade?" Narrativa escolar e seus matizes. ZAMBONI, Ernesta, GALZENARI, Maria Carolina B. e PACIEVITCH, Caroline. (org.). Memória, Sensibilidade e Saberes. Rio de Janeiro: Alínea Editora, 2015.

ROCHA, Helenice, REZNIK, Luís e MAGALHÃES, Marcelo de Souza (org.). Livros didáticos de história: entre políticas e narrativas. Rio de Janeiro, FGV, 2017.

STAMATTO, Maria Inês Sucupira. Historiografia e ensino de história através dos livros didáticos de história. In: OLIVEIRA, Margarida Dias de; CAINELLI, Marlene Rosa; OLIVEIRA, Almir Felix Batista de.

Ensino de História: múltiplos ensinos em múltiplos espaços. Natal: Ed. UFRN, 2008.

WHITE, Hayden. Teoria literária e escrita da história. Estudos

históricos. Rio de Janeiro, v. 7, nº 13, 1994.

. Meta-História: a imaginação histórica no século XIX. São

Paulo: Editora da Universidade de São Paulo, 2019.

Recebido em 21 de março de 2020. Aprovado em 21 de maio de 2020. 